on the ground that $I$ have found, after many years' trial, its solution in distilled water a most valuable external application for the cure of gout, rheumatism, tic doulouroux, and chronic inflammation, with enlargement of the joints (see LANCET, Nov. 15, 1834 , article on the romedial powers of the solutio iodidi polassii). Eight years have now elapsed since I called the attention of the profession to the efficacy of the solution of the iodide of potassium in chronic inflammation of the joints, whether arising from a specific or an accidental cause, after the usual rontine practice had frequently been baffled, even in affording relief. Long ere that period I was in the habit of prescribing it as the best external application for gout, rheumatism, \&c., and my confidence still remains unshaken in its curative powers.

Dr. Watson was silent on the modus operandi of the iodide of potassium, when exhibited internally for the cure of gout. The hiatus probably will in part be satisfactorily supplied by adding the following formula, which I invariably administer internally, as an adjunct to the lotion, viz. :-

$\mathrm{R}$ Powd. nitr. potass, 3iv; Potass. tart. of ant., gr. ij ; Sp. nitr. ather, $\mathbf{3}$; ; Water, or comp. infus., $\overline{3} \times j$. Mix.

Make a mixture. Dose, a wineglassful, morning, noon, and evening.

Although the above treatment has quite fulfilled the desired purpose, nevertheless I have no scruple in laying it aside for a season to try Dr. Watson's more simple method, and should the enemy again attack a young subject who has suffered most severely and frequently from gout, though not having yet reached the age of fifteen years, his case will be a fit one for trial, and the result shall be faithfully recorded in the instructive pages of ThE LanceT. Your obedient servant,

Princes-street, Nov. 26, 1842.

\section{POISONING BY THE INHALATION OF \\ IMPURE NITROUS OXIDE GAS.}

To the Editor,-Sir: The following case illustrates the peculiar effects produced by the inhalation of impure protoxide of nitrogen, or nitrous oxide :-Three young men had provided a bladder, containing two quarts of the nitrous oxide, for the purpose of exhibiting its exhilirating effects. One of them applied the bag in the usual way to his nostrils, and made about ten inspirations of its contents. Only a slight effect was produced, merely a reeling to and fro, as though labouring under intoxication, which state lasted about twenty seconds, when, thinking that sufficient inspirations had not been made, he again breathed the gas for a short time, and suddenly a series of the most violent muscular motions resulted, which re- quired the combined strength of his companions to control, and continued with unabated force for full ten minutes, when his efforts relaxed, and, apparently, the effects were subsiding, as he became conscious of his situation; but only a few minutes had elapsed before he again exhibited similar forcible movements, striking out in all directions. These alternate intermissions and violent muscular exertions continued for half an hour. In the intervals of the paroxysms his manner and conversation were exactly similar to what is witnessed in the delirium produced by inebriety. On my arrival, finding his pulse beating with most rapid strength, I directed free cold affusion over the head and face, and, opening the temporal artery, took away about ten ounces of blood. Complete success attended these measures, restoring perfect sensibility, the patient expressing himself as being unconscious in the slightest degree of all that had occurred. Contrary to the usual effect of pure nitrous oxide (which produces no after depression, unlike other stimuli), intense languor and fatigue were complained of. The young man recovered in a day or two, merely experiencing a throbbing sensation in the region of the forehead, and a sense of constriction and pain over the right hypochondrium, which were most intense on regaining sensibility, subsequently, gradually disappearing. On inquiry, I found that while preparing the gas from the nitrate of ammouia, the flame was urged too rapidly, and a slight explosion was heard, filling the retort with red vapours. The bladder was immediately removed, and the experimentalists knowing that decomposition of the vitrate had resulted, feared that the gas was contaminated with nitrous acid and nitrogen, the products of decomposition. They tested it by a single inspiration, and its supporting combustion. Perceiving no indications of impurity, they believed that the bladder was removed from the retort before the impure gas had entered, which unfortunately could not have been the case. The subject of the above remarks had previously, on many occasions, inspired the nitrous oxide, the effects being very transient, and consisting solely of muscular exertion. I am quite at a loss to account for the cessation of the motions and their subsequent renewal, resembling so rearly an epileptic attack. That the sense of constriction on breathing was produced by the nitrous acid vapour $\mathbf{I}$ have no doubt, although present in such minute quantity as to be undiscernable by the tests applied. Perhaps some correspondents will favour me with their opinions of this case, the details of which I sincerely hope will prove a caution to incompetent persons undertaking the manufacture and inhalation of the nitrous oxide. I am, Sir, yours obediently,

Lincolnshire, Nov. 21, 1842. 